\title{
Correlation between the Fashion Industry and the Development of Eating Disorders
}

\author{
Nikolett Bogár* \\ Institute of behavioural sciences, Semmelweis University, UK
}

Submission: February 07, 2018; Published: February 23, 2018

*Corresponding author: Nikolett Bogár, Institute of behavioural sciences, Semmelweis University, Hungary, UK, Email: nikolett.bogar@gmail.com

\section{Opinion}

Socio cultural influence has an important role in the background of eating disorders that occur in psychiatric practice more and more often. Eating disorders can be perceived also as a modern disease of civilization symptomatic of this age [1]. The cultural pressure of the thin ideal and learning through modelling have a great role in the development of eating disorders. This phenomenon is well-known in the background of several selfdestructive human behaviours (e.g., suicide, addictions). The thin models are primarily imitated by young people. According to the outcomes of Park's survey on the role of mass media (2005) the drive for thinness is increased by reading fashion magazines [2].

In our present study we analyse the narratives of the first author who was formerly a fashion model herself and the responses to her interview questions distributed among her fellow model colleagues. This study aims to investigate the correlation between the development of eating disorders and being employed in the fashion industry, as well as the pathological effect of the pressure for thinness, by using the personal experience of the author and other international models having worked in the fashion industry for several years.

Based on the responses we received from former high fashion models, there is a strong correlation between working in the fashion industry and having elevated risk factors of developing eating disorders. It is stated in almost every answer that we received from former models, that the influence of agents, stylists, fashion designers and in general the fashion industry's environment pressure high fashion models to a certain degree, where they even tend to use self- destructive methods to shape their bodies (e.g. severe calorie restriction, over-exercising, use of laxatives, self induced vomiting).

The author experienced all of the above mentioned first hand as she was working in the fashion industry for several years (2008-2013). Prior to starting her modelling career, she had been suffering from anorexia nervosa, that wasn't cured until quitting the fashion industry.
In her memoires, she states that she felt extremely anxious about her body measurements (hips, waist and bust), causing not only constant body dissatisfaction and insecurities about parts of her body that she wasn't even aware of beforehand but also self doubt about her personal values.

Her regime consisted of no more than 500-800calories per day, combined with extreme physical activity on a daily basis. Even though her agents were satisfied with her figure and size, she couldn't stop worrying about looking swollen in the pictures or not being able to fit into designer clothes. She refused to consume any food or even water before meeting her agents or having a photo shoot or doing a catwalk. This also resulted in constant body-checking whenever she could find the right moment for it. Body-checking meant putting her fingers around her upper arms or legs to see if they haven't became larger from one day to the other, looking at her abdominals in public mirrors, or touching her bones under her clothing.

Her agents usually pointed out the dark circles under her eyes, and gave her several tips to get rid of them, however, they potentially have been the cause of extreme fatigue and food deprivation.

Below we present quotes from the personal diary of hers:

"I have hardly eaten anything for two weeks. Not even fruit. Only green juice, celery, eventually pineapple and hot tea. I hardly have strength, I cannot think. But Maria (agent) said today that she had no idea what I am doing but I'm doing it really well, and I should keep on doing it. Sometimes I think I look ill. I am not too beautiful. But in New York I really have to be brutal thin. And I did it. Now there is no return."

"I have a terrible headache. I haven't eaten anything today, and I jogged 13kilometres in the morning. It would be nice to have some peaches or grapes. I feel like fainting but I'm not allowed to eat such fruit, they pure sugar, and I must lose weight, I'm fat, I know I'm fat." 
Based on the answers received from her fellow model colleagues, other high fashion models experienced quite the same pressure concerning their physique. The study group was internationally heterogeneous. A semi structured questionnaire was sent out to the objects via e-mail containing different questions about the modelling industry.

"Whenever I go to a polaroid test shooting at the agency, I feel tightness in my stomach."

"I once went to a casting abroad where they wondered how I could possibly get to the casting with such hip size, and they told me straightforward that there was no hope for me to get the job. The funny thing is that I did get the job... I have no idea how."

"I started as a fashion model when I was 15, and the first thing they said was that I had to lose weight in order to be able to work."

"I feel either in great shape or literally as a pig. These extremes alter from one minute to another and unfortunately this can be attributed to the fashion world."

Five female models fulfilled the DSM-5 criteria of anorexia nervosa or bulimia nervosa. Four of them were anorexic (body mass index: 13.9-15.3), one was bulimic. The symptoms of three people began before the model career, those of two models after it. 17 models reported that the model profession intensively increased the bodily preoccupations.

Our date highlights the health impact of cultural ideals, and calls the attention to prevention strategies. It would be an important measure to regulate the employment of fashion models. The unrealistic requirements make it harder and harder to enter the fashion industry, and to maintain a healthy lifestyle while pursuing the modelling career causing long term damages to fashion models both mentally and physically. This is important from epidemiological point of view since this aspect has an impact on the general population through the effect of idolizing fashion models.

\section{References}

1. Miller, Mary N, Andrés J P (2001) Culture and eating disorders: A historical and cross-cultural review. Psychiatry: Interpersonal \& Biological Processes 64: 93-110.

2. Park, Sung-Yeon (2005) The influence of presumed media influence on women's desire to be thin. Communication Research 32: 594-614.

\section{Your next submission with Juniper Publishers} will reach you the below assets

- Quality Editorial service

- Swift Peer Review

- Reprints availability

- E-prints Service

- Manuscript Podcast for convenient understanding

- Global attainment for your research

- Manuscript accessibility in different formats

( Pdf, E-pub, Full Text, Audio)

- Unceasing customer service

Track the below URL for one-step submission https://juniperpublishers.com/online-submission.php 